\title{
REAL LIFE LEARNING: THE DEVELOPING IMPORTANCE OF FORMAL AND INFORMAL PROFESSIONAL COMMUNITIES OF PRACTICE
}

Focus Group - 2

Magda Ritzen (Netherlands, Chair), Anne McDougall (Australia, Rapporteur) and Mike Kendall (UK, Rapporteur), Alexander Karapadis (Germany), Barbara Bamberger (Austria), Hannelore Dekeyser (Netherlands), Gina Reyes (Australia), Julia Walsh (Australia)

Key words: Professional, community of practice, real-life learning.

\section{INTRODUCTION}

The working conference has provided many examples of professional, formal and informal communities of practice that rely to a lesser or greater extent on access to and the use of ICT. The working definition we have used is based on the work of Wenger, McDermott and Snyder (2002) which states that a "Community of Practice is a group of people who share a (great) interest in a certain object, theme or knowledge domain. They meet [face-toface or virtual] to exchange, to develop and to make knowledge explicit, which arises from questions and problems they have."

\section{COMMUNITIES OF PRACTICE: EXAMPLES}

The operation of a Community of Practice $(\mathrm{CoP})$ reflects the needs of the members and their context. The members of the focus group have illustrated 

Rapporteur) and Mike Kendall (UK, Rapporteur), Alexander Karapadis (Germany), Barbara Bamberger (Austria), Hannelore Dekeyser (Netherlands), Gina Reyes (Australia), Julia Walsh

different kinds of practice from their professional domains of education, government and industry.

At the HvU, the University for Professional Education and Applied Science in the Netherlands following a conference on education innovation, interest lead to four CoPs being initiated: 'Testing and Assessment', 'Student coaching and Portfolio', 'Instruments in Education' and 'ICT and projectbased education'. The CoPs have approximately eight participants and meet face to face regularly (once every six weeks). Two CoPs had a relatively clear focus, i.e. a communal question, right from the start (e.g. How can a project-based approach to problems and assignments be best supported by ICT), while one CoP decided to let their agenda be composed of participants' questions. Another CoP had such a diverse set of questions that progress was severely hampered and eventually only 7 out of 15 participants remained. This CoP did manage to achieve communal results, but there is little remaining drive.

No fixed period was determined but even after a year, the participants (staff members) continue to find it worthwhile to attend CoP meetings. They meet and consult people who are working on the same things they are. In all the CoPs problems are discussed and experiences are exchanged; in some, attempts are made to generate explicit knowledge and ideas (e.g. what are the characteristics of project-based teaching) so that others may also benefit. In this way the CoPs play an important role in the professionalisation of the participants and satisfy important success criteria: demand-driven, to the point and on the job.

In Austria, teachers are using communities of practice in different ways: working together in project groups, working with students, exchanging files and discussing themes. One of the examples can be found in a consortium of teachers. In an online community they are discussing how to improve the teaching, how to integrate new media in class in learning a language. They are sharing information by exchanging files, they share news on this topic and are discussing in a forum and/or a chat. This $\mathrm{CoP}$ is a very agile form of cooperation in this consortium.

The British Computer Society (BCS) is the professional body for IT in the UK. It is a very large body of people who are loosely brought together having passed entrance exams and paid the necessary fees (i.e. membership is not free). In order to be effective, the members are organised into regional and special interest groups, and expert panels whose membership can overlap. For example, the Schools Expert Panel brings together 

professional communities of practice

educationalists to develop new understandings about ICT in education that can then be shared across the whole membership, and more widely. The BCS also works in other ways, crossing industry sectors, for example, bringing together members who live or work in an area to meet and share ideas around themes of general interest from their own experience with increased understanding. However, it seeks to support more 'informal' CoPs to bring together members around common themes, to promote learning and actions.

The growth of online tools and public policy to support 'communities' working together, whether they are CoP or even communities of interest, means it is far easier for people to start up a community, invite and advertise for new members. For example, the BBC provides a public service 'ICAN' it is free, anyone can set up a community locally and globally www.bbc.co.uk/ICAN

PROLEARN is an ongoing and free of charge network of excellence funded by the European Union with the aim to share knowledge in the area of professional training and qualification. The focus lies in building a European wide community of practice in professional learning and training tasks and is open for experts in research and economy who apply. The virtual competence centre www.prolearn-online.com is the central working and service platform of PROLEARN in the Internet. The centre enables experts of the service industry and research, to publish and use newest knowledge about innovative ideas, products and results from research and practice and the construction of network relationships ("research meets industry", "industry meets research"), supporting the transfer of knowledge. The community of practice offers options and services to share and receive knowledge in professional training: a knowledge pool in professional learning events, projects, partners, trends and news; an exchange platform with experts and power-user in professional learning; surveys about latest trends in the area of professional learning; a networking community in professional learning; you can post or upload your own events, publications, projects and news; find experts and information in professional learning tasks.

The target groups are: Intermediary organisations to spread wide the results of the competence centre; companies as end-users to name their requirements and find solutions or ideas to solve; research institutes and universities to bring their expertise in and find inspirations out of the requirements the companies bring; and companies as providers of services and products in professional training.

Consideration of the examples has lead to the identification of a range of attributes that can be modelled within an emerging framework. 

Rapporteur) and Mike Kendall (UK, Rapporteur), Alexander Karapadis (Germany), Barbara Bamberger (Austria), Hannelore Dekeyser (Netherlands), Gina Reyes (Australia), Julia Walsh

(Australia)

\section{QUESTIONS}

A clear focus of the discussion was how Communities of Practice can operate successfully. Success should mean that can a CoP supports Real-Life Learning and learning in general. The place and the function of $\mathrm{CoP}$ in the learning process needs to be clarified. Three categories of questions have been identified: 1) pedagogy, 2) organisation of learning including business model, 3) implementation of tools:

1. What are the benefits in the organisational and personal dimension which can be gained from a CoP? How can collaboration and the exchange of experiences be seen as a positive element in learning and innovating? In what ways does the $\mathrm{CoP}$ help to support a demanddriven and problem-based learning environment?

2. How can the CoP support the organisation of a meaningful learning process? What are the mission critical factors for learning and working in a CoP? What has to be agreed before starting a CoP? What are the conditions for starting, running and ending a CoP? What are the incentives for members and organisational assumptions (consumer relation management) to join and stay in a CoP? How can we create a win-win situation for all members by a balanced exchange of knowledge and experience? How can a CoP be embedded in a general information plan of the driving organisation? What are typical business models behind a successful CoP?

3. What are the typical functions and characteristics of a CoP? What are the skills which can be presumed from the participants? What role does usability play and what specific factors of functionality and design which have to be taken into consideration?

\section{EMERGING MODEL}

The considerations of the group have resulted in an emerging model that provides a framework to consider the questions we have proposed. The model supports the consideration of a series of general bi-polar attributes that have emerged from the examples presented above. 


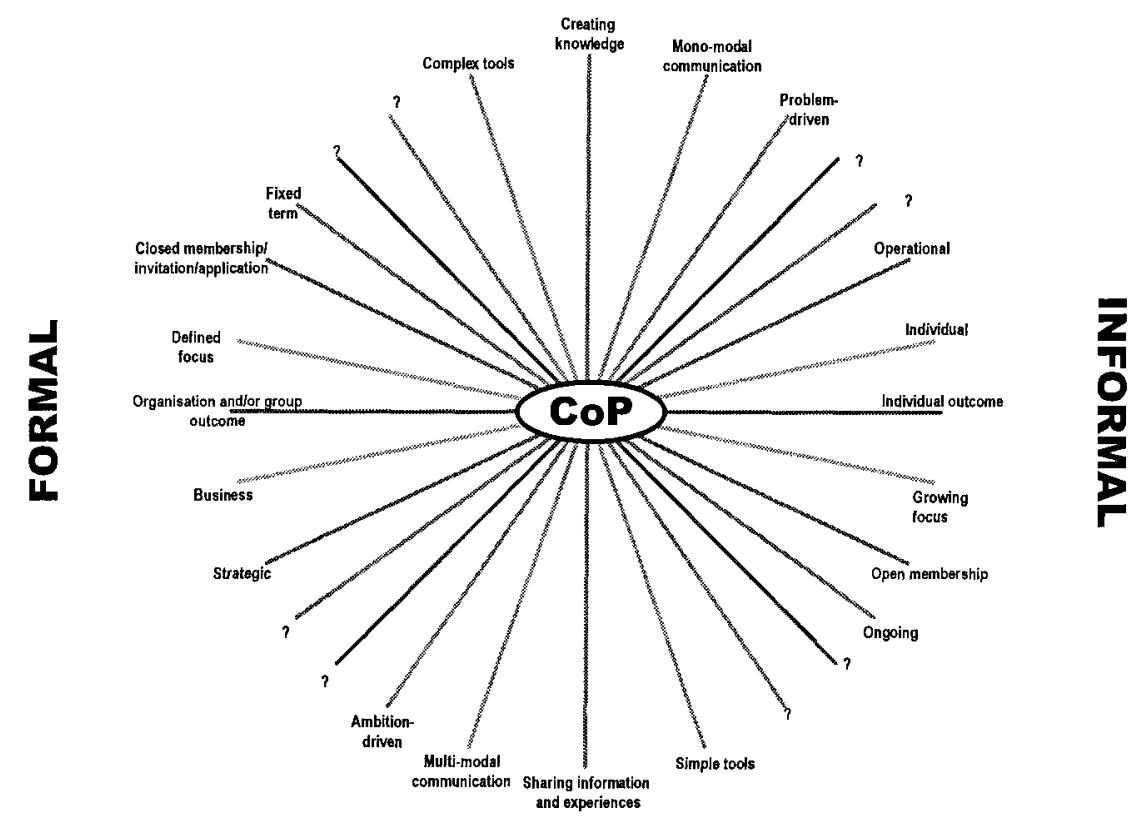

\section{ATTRIBUTES OF THE MODEL}

The attributes of the proposed model:

- Formality cannot be characterised by one attribute but a crucial characteristic is being more or less rule-based; to what extent are $\mathrm{CoP}$ members supposed to follow stricter rules, do they have freedom to determine the rules during CoP interaction or is everything strictly formulated in well defined working methods?

- Orientation/ expected outcome/ targets: CoPs can be oriented towards the individual (personal?) or to the business/ to organisational benefits. Slightly related to previous aspect, the orientation can focus on operational rather than on strategic needs.

- Driving factor: problem or ambition? The driving factors for CoPs can be problems, but also the desire to realise something, an ambition, or aspiration.

- The focus of a CoP can be well defined from the start, but a lot of times focus grows or shifts during the process. 

Rapporteur) and Mike Kendall (UK, Rapporteur), Alexander Karapadis (Germany), Barbara Bamberger (Austria), Hannelore Dekeyser (Netherlands), Gina Reyes (Australia), Julia Walsh

- Information or knowledge? CoPs vary from information sharing instruments to real knowledge creating entities.

- Duration: While certain CoPs have a fixed term, others are set up to be ongoing.

- The size can be limited or free.

- Membership can be open or closed (only on invitation or by application).

- Communication modes can be mono-modal (only one communication mode is used) or multi- modal (a variation of communication modes).

- Tool driven: in some CoPs the interaction is strongly steered by the tools in use, in other CoPs, the choice of tools is more free and steered by the needs of the members.

\section{APPLICATIONS OF THE MODEL}

The Focus Group has developed a model to represent these ideas about communities of practice and their characteristics. The model is illustrated by a set of axes. Each axis represents one of the characteristics we have listed, with opposites at each end. We include some additional axes marked with question marks to acknowledge that the model may not yet be exhaustive.

The Group is still working on deciding the most useful way of visualizing the model. The axes might be seen as all mutually orthogonal, defining a multidimensional space as is done in factor analysis; then an individual community of practice could be described by a multidimensional profile determined by its position or "score" on each of the axes. Alternatively, the diagram could be viewed as a two-dimensional one; this would allow for relationships among the characteristics to be illustrated by the relative positioning of their axes.

The Group sees three valuable ways in which this model can be used:

1. For research. For example, studies might assign "scores" on each of the axes for individual communities of practice and these could be related to the perceived extent and nature of their success, to improve understanding about the nature of successful communities of practice in particular contexts.

2. In establishment of communities of practice. Individuals or groups setting up a community of practice could use the model to structure 
planning and implementation, making decisions about positions along axes that will be most appropriate for the purpose of the community.

3. To provide a structure for discussion and/or improvement of the operation of existing communities of practice.

\section{RECOMMENDATIONS AND FUTURE OPTIONS}

The increasing importance of Communities of Practice, whether they are formal or informal, for the development of professional and vocational education is reported in this paper. The members of the Focus Group have proposed a model to analyse the effectiveness and to support the development of CoPs. It is at an early stage in its development with many questions still to be considered and answers proposed. It appears that the proposed model can be applied in many different communities, including education, industry, government and social contexts. The proposed model should help answer the three questions of pedagogy, organisation and tools and visualising solutions.

This paper raises issues of importance that should be matters for future research and consideration at IFIP conferences and working groups.

\section{BIBLIOGRAPHY}

Wenger, E. McDermott, R. and Snyder, W.M. (2002) Cultivating Communities of Practice; $a$ guide to managing knowledge Harvard Business School Press, Boston, Massachusetts 